\title{
Tip of the iceberg: congenital cataract with pre- existing posterior capsule defect (PPCD): how vital is the role of ultrasound biomicroscopy?
}

\author{
Srikanta Kumar Padhy, ${ }^{1}$ Anubha Rathi, ${ }^{2}$ Sohini Mandal, ${ }^{3}$ Meghal Gagrani ${ }^{2}$
}

'Ophthalmology, Dr Rajendra Prasad Centre for Ophthalmic Sciences, All India Institute of Medical Sciences, New Delhi, India

${ }^{2}$ Ophthalmology, Dr Rajendra Prasad Centre for Ophthalmic Sciences, All India Institute of Medical Sciences, New Delhi, India

${ }^{3}$ Ophthalmology, Dr Rajendra Prasad Centre for Ophthalmic Sciences, All India Institute of Medical Sciences, New Delhi, India

\section{Correspondence to}

Dr Srikanta Kumar Padhy, srikantkumar.padhy19@gmail. com

Accepted 14 June 2018

\section{DESCRIPTION}

A 14-month-old female child presented to the outpatient clinic with abnormal white reflex of the left eye (LE) noticed by parents for the last 6 months. The right eye (RE) had similar history and was operated for a white cataract at an outside hospital 3 months before. Intraoperatively, pre-existing posterior capsule defect (PPCD) was noted in the RE with inadvertent lens matter drop, which occurred after hydrodissection and was removed subsequently. The PPCD was quite large and the RE had to be left aphakic. Anterior segment examination of the LE with fully dilated pupil showed total cataractous lens with invisible posterior capsular details (figure 1A). Ultrasound biomicroscopy (UBM) of the LE showed a large posterior capsular defect with subluxation of the lens into the vitreous cavity ${ }^{1}$ beyond the capsule (figure 1B). Care was taken to avoid lens drop during irrigation-aspiration. Viscoat can be used to coat the area of the PPCD to temporarily seal the defect. Low bottle height and low parameters were used to prevent turbulence and chamber collapse. Hydrodissection was avoided in this case as there is high risk for enlargement of the PPCD (figure 2A). Limited anterior vitrectomy was done. No posterior capsulorhexis was performed as there was a pre-existing posterior capsular defect. The PPCD was trimmed with the vitrector to clear the visual axis and made more regular. A multipiece (three-piece) foldable intraocular lens was placed in the bag with optic capture in the anterior capsulorhexis (figure $2 \mathrm{~B}$ ). PPCD is often detected for the first time during surgery in total or mature cataracts. Although bilateral PPCD in the absence of a posterior polar cataract or posterior lenticonus is also reported, we believe that many of these eyes with PPCD might have

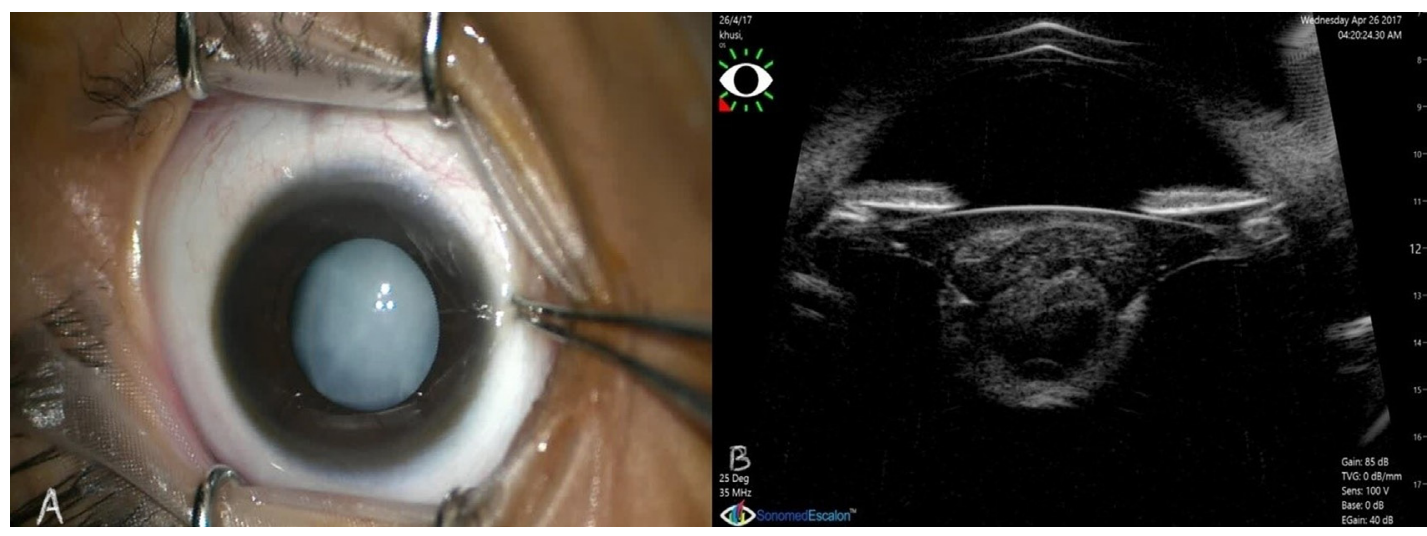

Figure 1 (A) Image of the left eye (LE) under the operating microscope showing total white cataractous lens. (B) Ultrasound biomicroscopic image of the LE depicting pre-existing posterior capsular defect with posterior subluxation of the lens beyond the posterior capsule.

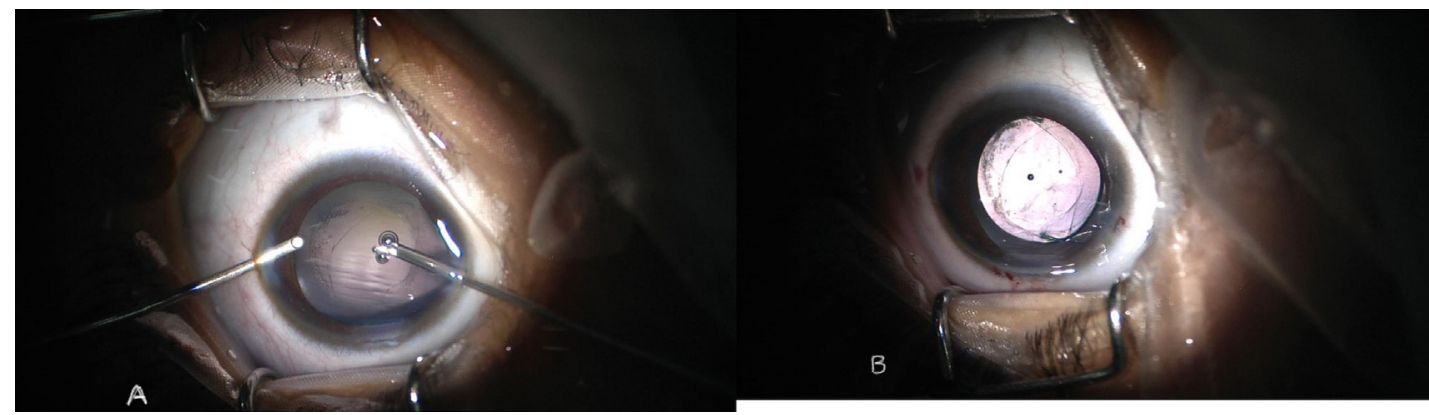

Figure 2 (A) Intraoperative image of the left eye under the microscope after lens aspiration showing a large posterior capsular defect. (B) Three-piece intraocular lens placed in the bag with optic capture. 
posterior lenticonus which thins out, causing microleaks and rapid maturation of the cataract with further thinning of PC, finally leading to PPCD. ${ }^{2}$ PPCD may be clinically suspected when a rapid transformation to a total white cataract from a non-mature cataract occurs. Other clinical signs described include fishtail sign, white demarcation line and white crystalline particles floating in the vitreous, ${ }^{3}$ but they may not be evident in all white cataracts with PPCD, such as in our case. Hence a total cataractous lens with PPCD is just the tip of

\section{Learning points}

All eyes with congenital total cataract must be examined for pre-existing posterior capsular defect.

- Establishing pre-existing posterior capsule defect (PPCD) and careful surgical planning may prevent inadvertent surgical complications.

- Apart from clinical signs, ultrasound biomicroscopy is an excellent tool to precisely localise the PPCD.

- Surgical modifications, including no hydrodissection, can save the eye from intraoperative complications such as unnecessary vitreous loss. the iceberg. It is recommended that before operating, the base of the iceberg should be looked for to avoid intraoperative complications. A preoperative UBM can be an excellent tool in this regard.

Contributors SM: discussed the planning. AR: conception of idea. MG: acquisition of data. SKP: conception and design.

Funding The authors have not declared a specific grant for this research from any funding agency in the public, commercial or not-for-profit sectors.

Competing interests None declared.

Patient consent Parental/guardian consent obtained.

Provenance and peer review Not commissioned; externally peer reviewed.

(C) BMJ Publishing Group Ltd (unless otherwise stated in the text of the article) 2018. All rights reserved. No commercial use is permitted unless otherwise expressly granted.

\section{REFERENCES}

1 Kaya A. Preoperative usage of ultrasound biomicroscopy in pediatric cataract. Arq Bras Oftalmol 2016;79:62.

2 Vajpayee RB, Angra SK, Honavar SG, et al. Pre-existing posterior capsule breaks from perforating ocular injuries. J Cataract Refract Surg 1994;20:291-4.

3 Vasavada AR, Praveen MR, Nath V, et al. Diagnosis and management of congenital cataract with preexisting posterior capsule defect. J Cataract Refract Surg 2004:30:403-8.

Copyright 2018 BMJ Publishing Group. All rights reserved. For permission to reuse any of this content visit

http://group.bmj.com/group/rights-licensing/permissions.

BMJ Case Report Fellows may re-use this article for personal use and teaching without any further permission.

Become a Fellow of BMJ Case Reports today and you can:

- Submit as many cases as you like

- Enjoy fast sympathetic peer review and rapid publication of accepted articles

- Access all the published articles

Re-use any of the published material for personal use and teaching without further permission

For information on Institutional Fellowships contact consortiasales@bmjgroup.com

Visit casereports.bmj.com for more articles like this and to become a Fellow 